\title{
Publisher's Editorial
}

The first issue of Paraplegia was published by E \& S Livingstone Ltd of Edinburgh in May 1963. The Journal was founded by Ludwig Guttmann, who continued to edit it until his death at the age of 80 . His dedicated commitment to the cause of disabled people was as apparent in the Journal as it was in everything else he did, and the publishers (by that time part of the Longman Group) were proud to publish special issues to mark both his 70th and his 80th birthdays.

After Sir Ludwig's death in 1980, Mr Phillip Harris took over as Editor, assisted by Mr James Cosbie Ross (and, more recently, by Mr Trevor Hughes). Mr Harris has not only maintained Sir Ludwig's tradition, but has also placed his own emphasis on a 'holistic' approach to the paralysed person. We should like to take this opportunity of thanking Mr Harris for his devoted work on the Journal's behalf.

The Journal has grown in its first quarter-century, from a quarterly publication (costing $\ell^{4}$ ) to a bi-monthly costing rather more; it now has a very considerable international readership among members of many disciplines, and its wide-ranging nature is reflected in the content of this Jubilee issue.

We at Churchill Livingstone take great pleasure and pride in our long association with Paraplegia, and we hope to see the Journal going from strength to strength in future years. It is appropriate that this issue looks not only at the present state of the art, but also at the way ahead, and we are already looking forward to publishing a Golden Jubilee issue in 2012! 